Uniwersytet Łódzki

artur.galkowski@uni.lodz.pl

\title{
ONOMASTYKA TRANSLATORYCZNA A TRANSLATORYKA ONOMASTYCZNA
}

Słow a tematyc zne: translatoryka, onomastyka, tłumaczenie nazw własnych, adaptacje

\section{WPROWADZENIE}

Czy możliwe i zasadne jest wyodrębnianie działu onomastyki, zajmującego się nazwami własnymi (NW) jednego języka w perspektywie ich translacji/tłumaczenia lub adaptacji w innych językach? Czy możliwe i potrzebne jest budowanie teorii oraz określanie metod analizy i narzędzi stosowanych w praktyce translatorskiej w przypadku działu translatoryki, który mierzy się z procesami translatorskimi nazw własnych? Wobec faktów onomastycznych notowanych w zasięgu kontaktów interjęzykowych oraz intersemiotycznych obydwa ujęcia onomastyki i translatoryki okazują się uzasadnione zarówno w studiach onomastycznych, jak i translatorycznych (traduktologicznych). Pierwsze nazywam onomastyką translatoryczną (OT), drugie - translatoryką onomastyczną (TO). Przenikanie się oraz powiązania OT i TO, a jednocześnie istnienie specyficznych problemów, rozpatrywanych na podstawie metodologii ściśle nazewniczych lub przekładowych, prowadzi do naturalnych powiązań obydwu dyscyplin. Nie jest to obszar marginalny badań translatorycznych i onomastycznych, tym bardziej w płaszczyźnie wspólnej (interdyscyplinarnej), która dąży do łączenia w jedno problematyki onomastyczno-translatorycznej.

Sądząc po zakresie materiału (nazwy własne w przekładzie) oraz zjawiskach natury językowej, kulturowej i interkulturowej, a także problemach z nimi powiązanych, OT i TO powinny być traktowane jako istotne i aktualne działy onomastyki oraz translatoryki. Ich istnienie oraz rozwój potwierdza zarówno tradycja dotycząca translacji/adaptacji NW, jak i powstające w ostatnim czasie opracowania, które z tym problemem się mierzą (i pod kątem opisowym, i praktycznym) ${ }^{1}$.

\footnotetext{
${ }^{1}$ Zob. np.: Bantas 1994; Fourment-Berni Canani 1995; Manini 2002; Moya 2000; Pierini 2001, 2006; Sanz Espinar 2006; Viezzi 2004, Wolnicz-Pawłowska 2014.
} 


\section{SPOJRZENIE HISTORYCZNE}

Onomastyka, a w zasadzie refleksja dotycząca NW, od początku ociera się o problem tłumaczenia/translacji (TNW), będący często podstawą ich upowszechnienia (zaistnienia w innym obszarze językowym). W kontekście historycznym (w Polsce XIV-XVII w.) można mówić wręcz o pewnej tendencji, niekiedy konieczności przekładu np. imion osobowych z języków klasycznych lub hebrajskiego na języki narodowe. Jest to rzadko uświadamiany fakt, który wiązany był i jest z narzędziem metodologicznym dominującym w diachronicznych badaniach onomastycznych (zob. Wolnicz-Pawłowska 2014: 210-212). W etymologii NW wskazywano często na podstawy obce, nie zawsze wyszczególniając sposób ich zaistnienia, tj. pierwotne tłumaczenie lub proces do niego zbliżony (adaptacja). Podam ewidentny przykład etymologii NW opartej na translacji: słowiańskie pod względem formy imię Bogumił jest kalką językową gr. Teofil. Przykład mniej ewidentny: ang. Bush jako nazwisko tłumaczone w nowej rzeczywistości (emigracyjnej), jako np. pol. Krzak (translacja onimizowanego apelatywu; fakt stwierdzony na podstawie danych metrykalnych, specjalnych aktów, spontanicznej rejestracji; forma „zamerykanizowana”); podobnie pol. Jeleń, nazwisko mogące być w niektórych przypadkach tłumaczeniem jid. Hersz lub Kirsz < niem. Hirsch (powstałe w wyniku zmiany nazwiska z zachowaniem maskowanej podstawy; por. amer. Yellen).

Inna ilustracja TNW w przestrzeni publicznej i jednocześnie historycznej to translacja onimów z powodów politycznych, religijnych, ideologicznych. Tego typu zabiegi mogą być przymusowe i sterowane. Przykładowo: w czasach faszyzmu we Włoszech dokonano daleko zakrojonego onomasticidio 'zbrodni na nazwiskach' (Tasso 2010). Mianowicie nadano etniczny (włoski) charakter ponad 2000 nazwiskom pochodzenia słowiańskiego (głównie słoweńskiego) w regionie Triestu i Gorycji (dekret królewski z 1926/1927 r. w sprawie wprowadzania włoskiej formy nazwisk pochodzenia obcego). Odbywało się to z użyciem bardzo wattpliwych, żeby nie powiedzieć — prymitywnych, asocjacji formalnych prowadzących do ogólnej italianizacji regionalnego antroponomastykonu, np. przez tłumaczenie apelatywnych podstaw nazwisk słoweńskich albo ich ,zwłoszczenie”, również paronimizację (fałszywy proces translacyjny, często z wykorzystaniem etymologii ludowej). Wybrane przykłady nazwisk słoweńskich przekształcanych („tłumaczonych”) na formy włoskie lub pseudowłoskie to np.: Starc - Vecchiet, Vodopivec - Bevilacqua, Golob - Colombi, Koronica - Corona, Jozin Geppini, Janossevich - Gianossi, Bisiak-Bisiacchi, Luznik-Lussi, KanturekCanturi, Karielovic - Cariello, Hovalc-Cavalli, Kocic-Cocci, Kup - Cuppo, Illincic - Gellini.

Historia pokazuje więcej tego typu przypadków, uzasadnionych aktualną przynależnością polityczną społeczeństwa lub terytorium, na którym dochodzi do adaptacji lub wprost przekładu onimów. Przykłady nazw miejscowości tłumaczonych z języ- 
ka polskiego na niemiecki bądź odwrotnie: Babiak (pow. lidzbarski) — Frauendorf, Biała Rzeka (obecnie dzielnica Wejherowa) - Weißfluß, Biały Kamień (obecnie dzielnica Wałbrzycha) - Weißstein, Czarna Huta (pow. gdański) - Schwarzhütte, Dąbrowica (pow. jeleniogórski) - Eichberg. Przykłady translacji hodonimów wrocławskich po odzyskaniu niepodległości (z niemieckiego na polski: An der Elisabethkirche — dziś ul. św. Elżbiety, Beckergasse (w pobliżu piekarni) — dziś ul. Piekarska, Bergstrasse - ul. Góralska (thumaczenie asocjatywne, przybliżone), Bischofstrasse - ul. Biskupia, Blaugrundweg — ul. Btękitna (w toponimii Wrocławia niem. Blaugrund 'Modry Potok'), Fleischergasse - ul. Rzeźnicza (do XVI nazywana też Ochsegasse, następnie Büttnerstrasse, co by wskazywało na zmianę dominanty cechów przypisanych do ulicy — z rzeźników przechodzącej do bednarzy; wybór tłumaczenia dotyczy formy pierwotnej, sięgającej być może dawniejszej jeszcze historii polskiej Wrocławia)².

TNW przybiera różne formy proceduralne (zob. Viezzi 2004; Sanz Espinar 2006). Nie zawsze można mówić o tłumaczeniu „właściwym” (zarówno w odniesieniu do zjawisk natury historycznej, jak i obecnych aktów nazewniczych, prowadzących do powstania onimu przekładanego, np. w kontekście literackim, ale również każdym innym, związanym z ogólnie pojętą komunikacją: społecznym, administracyjnym, naukowym, medialnym itd.).

\section{METODY TNW}

Jeśli przyjąć, że tłumaczenie to ustanawianie odpowiednika o identycznym bądź zbliżonym (interpretacyjnym) znaczeniu w języku docelowym (w przypadku NW co najmniej znaczeniu funkcjonalnym - deiktycznym, ale także konotacyjnym i referencjalnym, w uznaniu NW za jednostki synsemantyczne, por. Gałkowski 2005), to TNW polegać może na:

1) translacji etymologicznych podstaw apelatywnych (etymon apelatywny warunkiem zaistnienia NW) np. niektórych nazw osobowych i miejscowych (łac. Laurentius - pol. Wawrzyniec);

2) translacji składników apelatywnych o niezbędnym do funkcjonowania NW znaczeniu leksykalnym, np. opisowych nazw instytucji lub nazw miejscowych/ geograficznych z członem utożsamiającym: Europejski Trybunat Praw Człowieka = ang. European Court of Human Rights = fr. Cour européenne des droits de l'homme; ul./ulica $X=$ via $X=$ rue $X=X$ st./street (por. ul. Piotrkowska, via Piotrkowska, rue Piotrkowska, Piotrkowska st.);

3) adaptacji fonetyczno-morfologicznej NW lub jej członu do systemu innego języka, zgodnie: a) z prawidłami ewolucji formalnej, niekiedy daleko posuniętej

${ }^{2}$ Na podstawie: http://www.wratislavia.net/breslau_names.pdf (dostęp 4 IX 2016). 
i nierozpoznawalnej dla przeciętnego użytkownika, np.: pol. Idzi < łac. Aegidius (ucz. Egidiusz; fr. Gilles, ang. Giles [garlz], hiszp. Gil); pol. Marzena < intern. Maria (jedna z mocnych hipotez); spol. Ożep < łac. Iosephus, hebr. סוֹ Ioseph;

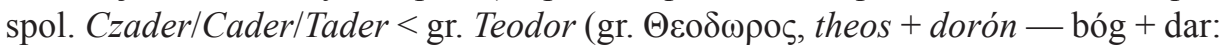
'dar boży, darowany przez boga'; v. kalka Bożydar) (Wolnicz-Pawłowska 2014: 206; według A. Cieślikowej (1996) — transpozycja fonetyczno-słowotwórcza); b) z normą i uwarunkowaniami przyjętej tradycji, np. pol. Monteskiusz (fr. Montesquieu), pol. Galileusz (wł. Galilelo Galilei), pol. Makiawel (wł. Machiavelli), dziś już niestosowanymi, bo trudno sobie wyobrazić, że np. Sarcozy będzie Sarkozjuszem czy Berlusconi Berluskoniuszem (por. Bantas 1994; Pierini 2006);

4) oddaniu nazw przyjętymi w onomastykonie języka docelowego odpowiednikami, np. Michat Aniot (wł. Michelangelo), Ludwik XIV (fr. Louis XIV), św. Szczepan

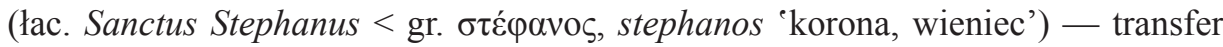
bezpośredni;

5) cytowaniu (kopiowaniu, zapożyczeniu) w formie fonetycznej (zachowanie brzmienia oryginalnego; transliteracja lub translokacja, por. Cieślikowa 1996): a) transliteracja $\mathrm{w}$ tym samym alfabecie, np. łacińskim: pol. Szekspir (ang. Shakespeare); b) transliteracja w innym alfabecie, np.: cyrylica $\rightarrow$ łaciński: ros. Путин $\rightarrow$ intern. Putin; łaciński $\rightarrow$ arabski: Yves Saint Laurent $\rightarrow$ نارول ناس في;

6) asymilacji homofonicznej (tam, gdzie pełna transliteracja fonetyczna nie jest możliwa), np.: systemy zachodnie $\rightarrow$ system chiński: intern. (amer. hybryda) Oreo $\rightarrow$ chiń. 餅乾; intern. Eastman Kodak Company $\rightarrow$ chiń. 伊士曼柯达公司; wł. Nutella $\rightarrow$ chiń. 能多益;

7) adideacji, czyli nadaniu obcemu proprium odpowiednika w postaci formy paronimicznej, która polega na podobnym brzmieniu lub zapisie, a jednocześnie wprowadza jakiś element znaczeniowy na poziomie apelatywnym, tworząc tym samym gry językowe (zazwyczaj w funkcji marketingowej, reklamowej); dotyczy to np. nazw słynnych marek przenoszonych na grunt chiński. Nie bez wydźwięku semiotycznego jest tu również przeniesienie pewnych wartości ikonicznych, np. cech graficznych, kolorów, kształtów, charakterystycznych elementów identyfikacyjnych logo/logonimu: Coca-Cola $\rightarrow$ chiń. 可口可乐 [kekoukele] 'smak i radość w jednym' (http://goodcharacters.com/blog/blog.php?id=79; dostęp 2 IX 2016).

\section{TNW W KONTEKŚCIE LITERACKIM}

Sposoby TNW podlegają głównie metodologii rozpatrywanej z punktu widzenia OT. Można wskazać jeszcze na inne, kwalifikowane w kategoriach TO w celu dyskursywnym, mianowicie w tekście literackim, a tym samym — w przekładzie artystycznym (stylistycznym). TO w obszarze literackim realizuje się przez zastosowanie kilku metod, wyodrębnionych m.in. za L. Fernandesem (2006): 
1) substytucja - zastępowanie form onimicznych bez zmiany odniesienia referencyjnego, np. w brazylijskim thumaczeniu na portugalski Harry'ego Pottera zamiast potencjalnych imion bohatera Harvey i Harold użyto imion Ernesto i Eduardo, zachowując intencję autorki (m.in. przez pozostawienie identycznych inicjałów w parze imion, niejako ,pierwszych z brzegu”): oryg. port.: Jamais vira o menino. Talvez fosse Ernesto. Ou Eduardo, oryg. ang.: He'd never even seen the boy: It might have been Harvey: Or Harold;

2) odtworzenie neologiczne - rodzaj kreacji ponowionej, która pozwala na utworzenie neologizmu w tekście docelowym T2 (niekiedy motywowanego apelatywnie) zamiast oryginału $\mathrm{z}$ tekstu wyjściowego $\mathrm{T} 1$ przy zachowaniu określonych wykładników stylistycznych; jest rodzaj substytucji motywowanej kreatywnie i prowadzącej do powstania onimu dotąd nienotowanego, np. port. Senhor Olivaras vs ang. Mr Ollivander (Harry Potter); oryg. port.: O Sr. Olivaras chegara tão perto que ele e Harry estavam quase encostando os narizes; oryg. ang.: Mr Ollivander had come so close that he and Harry were almost nose to nose;

3) usunięcie/ekspulsja - eliminacja NW z tekstu (metoda drastyczna, często prowadząca do zubożeń, o których czytelnik T2 nie ma świadomości; jest to zatem rodzaj translatorycznego nadużycia, jakkolwiek zazwyczaj dotyczy NW o mniejszym znaczeniu w toku narracyjnym). Przykład ekspulsji całkowitej: w przekładzie brazylijskim Harry'ego Pottera brak translacji zdania z NW Gregory the Smarmy: Bet it's that one behind the statue of Gregory the Smarmy that we found in our first week. See you. Przykład ekspulsji częściowej: oryg. port.: Naquela época vivia em Londres uma garota que se chamava Polly; oryg. ang.: And in those days there lived in London a girl called Polly Plummer;

4) dodanie - rodzaj deskrypcji adideacyjnej; uzupełnienie NW o dodatkowy element (informacyjny), który pozwala ją łatwiej zrozumieć, przyporządkować, zinterpretować, albo zastąpienie o naturze apelatywnej (czytelnej). Przykład: oryg. port.: Falou o Sr. Castor, finalmente:-Bem, em nome de Aslam, quem são vocês?; oryg. ang.: ,,Well?" said the He-Beaver at last. ,What, in the name of Aslan, are these?" (portugalskie nazwy zwierząt zazwyczaj mają jedną formę dla rodzaju męskiego i żeńskiego, stąd $S r$. $=$ Senhor , ale jest to w zasadzie oddanie pragmatycznej intencji wyrażonej w ang. He-Beaver). Por. pol. Walenty z krzywa gębaros. Валентий Криворотый (W. Reymont, Chtopi; zob. Ginter 2008: 51); pol. Niziołek - wł. Mezzuomo (z sagi o Wiedźminie A. Sapkowskiego, w tłumaczeniu na włoski Lo Strigo).

Spektrum metod TO w kontekście literackim z pewnością się na tym nie zamyka. Jest to przedmiot wielu obecnych badań, również w odniesieniu do różnych typów tekstu (epicki, poetycki, ale także informacyjny, użytkowy, choć w przypadku dwóch ostatnich kreatywność nie jest zalecana; chodzi raczej o terminologiczną standaryzację; por. np. Bonelli 2007; Salmon 2007). 


\section{TNW W KONTEKŚCIE MEDIALNYM}

Metody TO literackiej (artystycznej) przekładają się również na inne formy komunikacji, głównie o charakterze medialnym i ludycznym (np. w twórczych translacjach nazw miejsc i bohaterów kreskówek bądź programów dokumentacyjnych). Przykład z tego zakresu, to efekty zastosowania TO w Smerfach (rodzaj odtworzenia neologicznego lub adideacji motywowanej apelatywnie - cechującej). Punktem odniesienia jest francusko-belgijski oryginał $\mathrm{z}$ formami syntetycznymi lub analityczno-opisowymi (Les Schtroumpfs, autor: Peyo, pierwsza seria: 1958). Odpowiedniki polskie, amerykańskie oraz włoskie imion Smerfów z powodzeniem realizują swoje funkcje stylistyczno-ekspresyjne. Technika translatorska polega na wyborze formy nawiązującej do znaczenia leksykalnego nazwy typu przezwiskowego (tłumaczonej w sposób właściwy): fr. Les Schtroumpfs, pol. Smerfy, amer. The Smurfs, wł. Puff; fr. Le Grand Schtroumpf, pol. Papa Smerf, amer. Papa Smurf, wł. Grande Puffo; fr. La Schtroumpfette, pol. Smerfetka, amer. Smurfette, wł. Puffetta; fr. Le Schtroumpf à Lunettes, pol. Ważniak, amer. Brainy Smurf, wł. Quattrocchi; fr. Le Schtroumpf Costaud, pol. Osiłek, amer. Hefty Smurf, wł. Forzuto; fr. Le Schtroumpf Maladroit, pol. Ciamajda, amer. Clumsy Smurf, w1. Tontolone; fr. Le Schtroumpf Gourmand, pol. Lasuch, amer. Greedy Smurf, wł. Golosone; fr. Le Schtroumpf Grognon, pol. Maruda, amer. Grouchy Smurf, wł. Brontolone; fr. Le Schtroumpf Berger, pol. Wetniak, amer. Wooly Smurf, wł. Lanoso.

Warto zauważyć, że wzorem dla nazewnictwa w serii kreskówek i komiksów ze Smerfami mogły być imiona siedmiu krasnoludków z bajki braci Grimm. Tu również obserwuje się nacechowaną kreatywność interjęzykową: pol. Mędrek, Gburek, Śpioszek, Nieśmiałek, Śmieszek, Apsik, Gapcio; wł. Dotto, Brontolo, Pisolo, Mammolo, Gongolo, Eolo, Cucciolo; fr. Prof, Grincheux, Dormeur, Timide, Joyeux, Atchoum, Simplet; ang. Doc, Grumpy, Sleepy, Bashful, Happy, Sneezy, Dopey (por. Cámara Aguilera 2008).

Innym ciekawym przykładem translacji medialnej opisywanego typu jest tłumaczenie imion bohaterów programu przyrodniczego o gromadzie surykatek (oryg. Meerkat Mannor, twórca: Caroline Hawkins, 2005-2008; wersja pol. Rezydencja surykatek). Zwierzętom nadano w serialu imiona lub pseudonimy upodabniające ich relacje do relacji między ludźmi (w rodzinie, między klanami). Jest to rodzaj thumaczenia stylistycznego, wykorzystującego pewne idee i asocjacje. W wersji polskiej, podobnie jak w innych, tłumacze zastosowali odpowiedniki imion (wiele z nich w postaci hipokorystycznej), dostosowane do określonych cech, np. płciowych, wiekowych, fizycznych, hierarchicznych, estetycznych: Róża, Michałek, Hieronim, Karolek, Marian, Nina, Zorro, Majka, Gloria, Rajmund, Sonia; grupy: Wasacze, Kasacze, Starscy, Ogonowscy, Aztekowie. W wersji angielskiej oprócz antropologizacji, osiagnnięty został również efekt ludyczny przez nawiązania do kultury, np.: grupa The Whiskers (pol. Wasacze): Flower, Yossarian, Shakespeare, 
Tosca, Daisy, Pookie, Mitch, Rocket Dog, Axel, Sophie; grupa Starsky: Mozart, Carlos, Kinkajou, De La Soul.

\section{ZAŁOŻENIA OGÓLNE DOTYCZĄCE OT/TO}

Obserwacja faktów związanych z procesami translatorycznymi NW prowadzi do konstatacji, które można uznać za teoretyczne założenia OT/TO. Oto kilka z tych założeń, mogących stanowić asumpt do dalszej dyskusji naukowej.

TO rozwija się w sposób implicytny lub eksplicytny w obszarach formalno-kategorialnych onimii każdego typu: antroponimii, toponimii i chrematonimii, w tym np. ideonimii, obejmującej tytuły dzieł artystycznych (m.in. filmów i festiwali, zob. np. Naruszewicz-Duchlińska 2016; Berezowski 2004), oraz socjoideonimii (tu m.in. nazwy stowarzyszeń i fundacji, partii, organów).

Z drugiej strony OT pozwala na podejmowanie badań na poziomie kulturowym lub transkulturowym (zob. Arcaini 1992), np. w odniesieniu do sfery religijnej, militarnej, politycznej, artystycznej, medycznej, rozrywkowej, sportowej, ogólnie — terminologicznej; por. np. kwestię międzynarodowych kryptonimów operacji wojskowych: Operacja Orle Pióro przeprowadzona przez Polaków podczas wojny w Afganistanie w 2001 r. (ang. Eagle’s Feather) bądź Amber Fox (pol. Bursztynowy Lis), operacja NATO na terytorium Macedonii w latach 2001-2003, z udziałem kontyngentu polskiego. Z punktu widzenia OT interesujące jest ustalanie w podobnych przypadkach motywacji translacyjno-nazwotwórczych.

Metody oraz wyniki badań OT mają wymiar synchroniczny, ale również diachroniczny. OT gromadzi dane, które pozwalają prześledzić ewolucję transferu między językami NW, głównie antroponimów, dokumentowane np. w słownikach imion, potwierdzających procesy translacyjne (zob. np. KsImŚw), ale także toponimów, $\mathrm{np}$. w procesie standaryzacji nazw geograficznych typu egzonimicznego na poziomie użycia oficjalnego (zob. serię NGŚ oraz TGP/PPT).

OT może się krystalizować jako dział onomastyki wnoszący wiele cennych spostrzeżeń do TO; ustala choćby stopień proprialności jednostek uznawanych w praktyce translacyjnej za NW:

1) stopień maksymalny - imiona, nazwy geograficzne; większość antroponimów i toponimów realnych, ale również ze świata fikcji literackiej (nazwy spełniające podstawową funkcję identyfikacyjna, bez funkcji stylistycznej, konotacji);

2) stopień wysoki - przezwiska, przydomki, pseudonimy; urbanonimy, np. nazwy ulic; nazewnictwo literackie w funkcji stylistycznej, m.in. symbolicznej, asocjatywnej;

3) stopień średni - nazwy handlowe, nazwy przedmiotów, urządzeń, produktów przemysłowych, tytuły dzieł, przedsięwzięć, nazwy instytucji (również opisowe), nazwy programów europejskich, ogólnie — chrematonimia; 
4) stopień niski - etnonimy, nazwy przedstawicieli grup społecznych, np. członków partii, oficjalne i potoczne (również na użytek określonego dyskursu, np. polemicznego, krytycznego, ironizującego), trudne do przetłumaczenia, np. potocznie i okazjonalnie przedstawiciele KOD — kodacy, kodeiści, kodumiśsi, koderaści, kodziarze, koderzy;

5) stopień minimalny (jednostki językowe odbierane jako NW), np. kody i nazwy pierwiastków ( $K$, potas); nazwy techniczne i artystyczne kolorów; niektóre nazwy gatunkowe, szczególnie w kontekście handlowym.

Powyższe zestawienie prowadzi do wniosku, że przetłumaczalność NW (ang. traductibility of proper names) wzrasta wraz ze spadkiem stopnia proprialności.

OT pozwala określić, czy coś jest translacją danej NW, czy nią nie jest, a co najwyżej pozostaje dopuszczalnym lub jedynym możliwym odpowiednikiem, np. jest translacją imienia łac. Laurentius pol. Wawrzyniec; jest translacją tytułu i nazwy typu antonomazycyjnego fr. Tartuffe (z komedii Moliera Tartuffe, ou l'Imposteur, 1661) pol. Świętoszek (TO: nazwa tłumaczona powstała w wyniku odtworzenia i adideacji); jest translacją hipokorystyku fr. Jeannot pol. Jaś; jest translacją wł. Sant'Anna Matterza (hagionim oraz tytuł obrazu Leonarda Da Vinci) pol. Święta Anna Samotrzecia (Samotrzeć); jest paratranslacją w1. Suore Benedettine Riparatrici del Sacro Volto di Nostro Signore Gesù Cristo pol. benedyktynki obliczanki (Zgromadzenie Sióstr Benedyktynek od Wynagrodzenia Najświętszemu Obliczu Chrystusa Pana) albo fr. Filles de la Charité pol. szarytki lub wincentynki (Zgromadzenie Sióstr Miłosierdzia św. Wincentego à Paulo); nie jest translacją właściwą wł. Italia pol. Włochy; nie jest translacją właściwą intern. św. Adalbert pol. św. Wojciech; nie jest translacją uzasadnioną historycznie łac. Vitelus/Vitellius pol. Ciołek (domniemane nazwisko Erazma Ciołka Vitela z XIII/XIV w., Vitelo to raczej zdrobnienie od Vito/Gwido).

TO nabiera życia zarówno w studiach teoretycznych z ogólnej translatoryki/ traduktologii, w tym głównie w przekładoznawstwie literackim, ale też w praktyce tłumaczeniowej różnego typu dyskursów (kreując instrumentarium translacji napotykających problem przekładu NW; powstają poradniki dotyczące TNW, zob. np. zalecenia pomieszczone w VT).

OT i TO wykazują wiele wspólnych lub zbliżonych w analizie pól badawczych; mogą się także uzupełniać w kontekście interdyscyplinarnym. Efektem takiej „współpracy” są choćby projekty słowników bidyrekcjonalnych NW; podobnie dwukierunkowe słowniki eponimów i antonomazji bądź frazeologii opartej na NW z odpowiednikami międzynarodowymi (zob. np. SFE), słowniki lub glosariusze konkretnych terminologii onimicznych (np. STNU). 


\section{LITERATURA}

Arcaini E. 1992: La traduzione come operazione transculturale, „Lingua e Stile” XXVII (2), s. 157-181 .

Bantas A. 1994: Names, Nicknames and Titles in Translation, „Perspectives. Studies in Translatology” 2 (1), s. 79-87.

Berezowski L. 2004: Skq̨d się biora polskie tytuły amerykańskich filmów?, [w:] W. Kubiński, O. Kubińska (red.), Przekładając nieprzektadalne II, Wyd. UG, Gdańsk, s. 313-324.

Bonelli E. 2007: „Must a name mean something?” La traduzione del nome proprio in Lewis Carroll, „Il Nome nel testo” IX, s. 43-48.

Cámara Aguilera E. 2008: The Translation of Proper Names in Children's Literature, „E-F@-BULATION/E-F@BULAÇÕES” 2, http://ler.letras.up.pt/uploads/ficheiros/4666.pdf, (dostęp 20 IX 2016).

Cieślikowa A. 1996: Jak „ocalić w thumaczeniu” nazwy własne?, [w:] M. Filipowicz-Rudek, J. Konieczna-Twardzikowa (red.), Między oryginatem a przektadem, II: Przektad, jego tworzenie się $i$ wplyw, Universitas, Kraków, s. 311-320.

Fernandes L. 2006: Translation of Names in Children's Fantasy Literature, „Translation Studies” 2, s. 44-57, https://www.researchgate.net/publication/237246131_Translation_of_Names_in_Children's_Fantasy_Literature_Bringing_the_Young_Reader_into_Play_i (dostęp 10 IX 2016).

Fourment-Berni Canani M. 1995: Le statut des noms propres dans la traduction, „Rivista internazionale di tecnica della traduzione" 1 , s. 109-120.

Gałkowski A. 2005: Verso una semantica del nome proprio, [w:] K. Bogacki, A. Dutka-Mańkowska (ed.), Les relations sémantiques dans le lexique et dans le discours, UW, Warszawa, s. 109-118.

Garzone G. 2007: I nomi dei personaggi nei cartoni animati di Walt Disney nella prospettiva traduttologica, RIOn XIII (1), s. 151-166.

Ginter A. 2008: O przekładzie nazw osobowych w rosyjskojęzycznej wersji Chłopów Władysława Stanistawa Reymonta, „Acta Universitatis Lodziensis. Folia Linguistica Rossica” 4, s. 39-53.

KsImŚw - H. Fros SJ, F. Sowa, Księga imion i świętych, WAM, Kraków 1996-2007.

Manini L. 2002: I nomi significanti nella letteratura. Le loro forme e funzioni, e la loro traduzione, „Testo a fronte" 27, s. 29-56.

Moya V. 2000: La traducción de los nombres propios, Ediciones Cátedra, Madrid.

Naruszewicz-Duchlińska A. 2016: Onimiczna kreatywność translatorska w tytułach filmów i seriali, „Prace Językoznawcze” XVIII (3), s. 145-156.

NGŚ - Nazewnictwo geograficzne świata, GUGiK, Warszawa, 12 zesz., 2004-2010, http://ksng.gugik. gov.pl/wydawnictwa_ngs.php (dostęp 15 IX 2016).

Pierini P. 2001: La traduzione come processo di problem-solving, [w:] P. Pierini (ed.), Lo sviluppo della competenza traduttiva. Orientamenti, problemi e proposte, Bulzoni, Roma, s. 123-153.

Pierini P. 2006: Antroponimi inglesi e traduzione, ,Quaderni Internazionali di RIOn 2. RIOn International Series 2. Lessico e Onomastica 2", s. 225-240.

Salmon L. 2007: Sui titoli come onimi e sugli onimi dei titoli: onomasiologia creativa e traduzione dei «marchionimi» letterari, „Il Nome nel testo” IX, s. 93-105.

Sanz Espinar G. 2006: La traduction des noms propres (français - espagnol), Dialnet, http://dialnet. unirioja.es/servlet/oaiart?codigo=4031567 (dostęp 15 IX 2016).

SFE — Ludzie i miejsca w języku. Stownik frazeologizmów eponimicznych, oprac. M. Czeszewski, K. Foremniak, red. M. Bańko, Wyd. UW, Warszawa 2011.

STNU - A. Szwajczuk, Stownik ttumaczeń nazw uczelni wyższych w Polsce na język angielski/ Translation Glossary of Tertiary School Names in Poland. Polsko-angielski stowniczek wydziałowy, Wydz. Nauk Ekonomicznych UW, 2009, http://www.procesbolonski.uw.edu.pl/dane/Slowniczek WNE_2009.pdf (dostęp 13 IX 2016). 
Tasso M. 2010: Un onomasticidio di Stato, Mladika, Trieste.

TGP/PPT - Toponymic Guidelines of Poland for Map Editors and Other Users/Polski przewodnik toponimiczny dla redaktorów map i innych użytkowników, GUGiK, Warszawa, 2010.

Viezzi M. 2004: Denominazioni proprie e traduzione, LED, Milano.

VT = Vademecum thumacza. Wskazówki redakcyjne dla tlumaczy, Departament Języka Polskiego, Dyrekcja Generalna ds. Tłumaczeń Pisemnych, Komisja Europejska, Luksemburg 2007-2015, http://ec.europa. eu/translation/polish/guidelines/documents/styleguide_polish_dgt_pl.pdf (dostęp 10 IX 2016).

Wolnicz-Pawłowska E. 2014: Nazwy własne w przekładzie. Zarys problematyki, „Poznańskie Spotkania Językoznawcze" 27, s. 201-214, http://pressto.amu.edu.pl/index.php/psj/article/view/621/543 (dostęp 10 IX 2016).

\section{TRANSLATION ONOMASTICS AND ONOMASTIC TRANSLATION STUDIES}

\section{SUMMARY}

The article presents the basic assumptions of onomastics and translation studies that deal with the translation of names. One of those disciplines is called translation onomastics, and the second one onomastic translation studies. By the translation of names one should understand a series of processes that can consist of the proper translation, but also of the adaptation of the formal onymic units. Translation of proper names depends on propriality - the lower it is, the easier it is to translate a name. Name translation has a historical dimension - it becomes the basis of the new name created in a language. The most characteristic phenomena of translation of proper names are observed in the literature and the media discourse. The article presents the illustrations of these phenomena.

K e y w o r d s: translation studies, onomastics, translation of proper names, adaptations 